\title{
Lightweight concrete of continuous structure without fine aggregate
}

\author{
Alexandr Chiknovoryan ${ }^{1, *}$, Sergey Mizuryaev ${ }^{1}$, and Anna Zhigulina $^{1}$ \\ ${ }^{1}$ Samara State Technical University, Academy of Architecture and Civil Engineering, \\ Molodogvardeyskaya St., 194, Samara, 443001, Russia
}

\begin{abstract}
The study deals with basic properties and area of application of lightweight concrete of continuous structure without fine aggregate. When fine aggregate is excluded from the concrete structure, it becomes lightweight, has lower thermal conductivity and cost, simpler production technology. It also has durability sufficient for wall panels, water resistance, frost resistance and a number of other indicators. The paper describes additives used for concrete air entrainment. Using these additives does not complicate the production technology of panels, the panels can be easily transported and have sufficient stability and durability upon storage. The article justifies effective application of light concrete with continuous structure without fine aggregate in low-rise construction. Light concretes of continuous structure without fine aggregate allow to completely exclude the use of fine aggregate, to sharply reduce density and thermal conductivity of concrete, as well as to reduce moisture content and humidity of products, improve their cohesion and workability and get a number of other benefits. The study shows that light concrete without fine aggregate numerous advantages prove that it will be used in construction practice for a long time.
\end{abstract}

\section{Introduction}

The production organization of multilayered wall panels is associated with a deep technological process restructuring, as well as the need to provide the production with expensive thermal insulation materials. Under these conditions, it is obvious that there is a need to find effective ways to increase the thermal insulation capabilities of single-layer structures [1-6].

At the same time, it should be taken into account that a branch of industry for the production of light aggregates and industry of prefabricated reinforced concrete plants oriented towards it with the primary production of single-layered wall panels have been created

One more feature of the buildings use with multi-layered enclosing structures should be noted. Single-layer walls of concrete are vapor permeable.

* Corresponding author: umu-sgasu@mail.ru 
Three-layered walls contain vapor-proof insulation in the middle layer, and therefore the creation of $\backslash$ healthy microclimate in the premises is impossible without the organization of forced ventilation and air humidity regulation in the building by installing an airconditioning system. Otherwise, the microclimate deteriorates sharply, the humidity of air and constructions increases greatly, a number of diseases of the circulatory and respiratory organs occur; the immune system is suppressed; allergic reactions in the body take place, and the saved heat leaves through the ventilation pane during rooms airing.

\section{Materials and methods}

So, we could make a conclusion that the way out of this situation is to find effective technological ways to reduce the density of lightweight concrete in single-layer panels of external walls.

Reduction of lightweight concrete density and, as a result, its thermal conductivity occurs with lightweight aggregate content increase and its density and solution component decrease, which can be achieved by its porosity.

However, in this case, the concrete strength also decreases, so in practice it is necessary to look for an optimal ratio in the properties of raw material and concrete to achieve its desired parameters in the best way.

One way to solve this problem is to reduce the density of lightweight aggregate. The packed density reduction of produced lightweight aggregate is an important, but insufficient, condition for adjusting the thermal properties of wall panels to adequate.

Under these conditions, the most promising direction is considered to be the production of lightweight concrete of continuous structure without fine aggregate with various airentraining surfactants.

These substances, having been diluted with water and aerating with the help of mechanical or pneumatic methods, can give fairly stable foam. Freshly prepared foam consists of small air bubbles with thin shells from aqueous solution of a foaming agent. If the foam taking into account the use of different stabilizers is more or less stable, it manages to occupy a certain volume in lightweight concrete, to displace some of the fine aggregate and thus reducing the density of the concrete.

Concrete mixture preparation technology consists of the following stages: after loading the aggregate, cement and water into the mixer and its pre-mixing, the foaming agent concentrate is fed into the mixer and the mixture is mixed until it is ready.

In this case, the inter-grain space of the lightweight aggregate is replaced by a porous cement test consisting of minute closed pores, and that provides the porous concrete production with reduced density and reduced thermal conductivity.

Foaming additives, possessing the ability of air entrainment, reduce the surface tension of films on solid particles, thus contributing to the formation of very small air poresspheroids.

In this case, the role of additives is to transform large air holes unevenly distributed in concrete into many small air bubbles of spherical shape rather than to introduce air into concrete. These bubbles, located between the grains of aggregate, are enveloped with thin films having surface tension. Replacing the sand grains the bubbles reduce the tangential grip between the aggregate grains, while increasing the normal grip. As a result, the concrete mixture with entrained air resembles a jelly-like mass, possessing a lower coefficient of internal friction and, consequently, having better remolding effect and an increased ability to withstand the delamination in various technological processes. Moreover, the concrete mixture with the entrained air is less susceptible to water separation, since air bubbles block the channels through which water circulates, the latter not being able to crush bubbles above atmospheric pressure. 
The smallest air bubbles, fulfilling the role of aggregate and enriching its grain composition in fine fractions, provide the most significant increase of remolding effect and lower delamination in concrete mixtures with a low binder content. Structural lightweight concretes for wall structures primarily belong to such mixtures.

When determining the influence of lightweight concrete composition on air entrainment processes it is necessary to distinguish the consumption effect of cement, aggregate, water and additives. The choice of the number of components and their ratio is associated with a given density of concrete, its strength and economic preconditions. In practice, when choosing the concrete composition or when preparing it, the ratio and total consumption of mainly solid components vary within a small range and do not have a significant effect on the processes of porosity.

\section{Experiments and results}

One of the effective types of lightweight concrete of continuous structure without fine aggregate is porous concrete on gravel with packed density of 200 to $500 \mathrm{~kg} / \mathrm{m}^{3}$. Gravel consumption in concrete is $1 \mathrm{~m}^{3} / \mathrm{m}^{3}$, and the consumption of cement M400 for obtaining this type of concrete grades from M35 to M100 varies from 300 to $400 \mathrm{~kg} / \mathrm{m}^{3}$. The porosity degree of concrete mixture depending on foaming agent and cement consumption is in the range of $8 \ldots 12 \%$.

Table 1 and Table 2 show the main properties of lightweight concrete.

Table 1. Cement consumption

\begin{tabular}{|c|c|c|c|c|}
\hline \multirow[t]{2}{*}{$\begin{array}{l}\text { Light gravel } \\
\text { density, } \mathrm{kg} / \mathrm{m}^{3}\end{array}$} & \multicolumn{4}{|c|}{$\begin{array}{c}\text { Cement consumption, } \mathrm{kg} / \mathrm{m}^{3} \text {, for concrete with strengh, } \\
\mathrm{MPa}\end{array}$} \\
\hline & 3,5 & 5,0 & 7,5 & 10,0 \\
\hline 200 & 400 & - & - & - \\
\hline 300 & 320 & 400 & - & - \\
\hline 400 & 280 & 350 & 400 & - \\
\hline 500 & - & 320 & 360 & 400 \\
\hline
\end{tabular}

Table 2. Concrete strength

\begin{tabular}{|c|c|c|c|}
\hline \multirow{2}{*}{$\begin{array}{c}\text { Cement } \\
\text { consumption, } \\
\mathbf{k g} / \mathbf{m 3}\end{array}$} & \multicolumn{3}{|c|}{ Concrete strength, MPa, depending on entrained air } \\
volume, \% \\
\cline { 2 - 4 } & $10-12$ & $8-10$ & $6-8$ \\
\hline 300 & 3,5 & 3,5 & 5,0 \\
\hline 350 & 3,5 & 5,0 & 5,0 \\
\hline 400 & 5,0 & 5,0 & 7,5 \\
\hline
\end{tabular}

Concretes with air-entraining additives unlike concrete without any of these additives have small pores that could hardly be visible being different in dissociation, and as a consequence possess sufficient water resistance and frost resistance with a smaller capillary leak and a lower hygroscopicity.

Various stabilizers, for example, polyvinyl acetate emulsions are added into aqueous solution of foaming agent to enhance the stabilization properties of concrete mix and foam stability.

The problem of structure homogeneity increasing of lightweight concrete is solved by the choice of method and formation time of the product, as well as the conditions for its hardening. The porosity of lightweight concrete is characterized by entrained air volume and the uniformity of its distribution. Such concrete has mostly a closed porosity with an average pore diameter of about $0.001 \mathrm{~m}$. 
One of the main factors for obtaining high-quality lightweight concrete is the use of effective foaming agents, as well as highly disperse mineral components.

For example, dry fly ash from coal combustion in thermal power plants is an active mineral component. At power stations dry ash collecting is carried out in electrostatic precipitators with subsequent pneumatic removal into surge silos. The manufacturer in this case receives fine-dispersed ash in dry form for the concrete production. High dispersion corresponding mineralogical structure and hydraulic activity ash make it one of the most efficient and convenient types of active mineral additives for lightweight concrete manufacture. Suitability of using ash in the construction materials and products industry depends on its chemical composition, mineralogical structure, and also on physical properties. Physical and chemical properties of the sol, in turn, depend on the solid fuel type being combusted, and also on the method of its selection in thermal power plants.

The technology of manufacturing concrete with the addition of ash is similar to the ordinary concrete production. The ash is added into the concrete mixer in dry form through a separate bunker in the amount of up to $30 \%$ of the cement weight. The technology of laying lightweight concrete with the addition of ash is similar to the technology of laying concrete without it.

Examples of external walls characteristics from lightweight concrete with external and internal finishing layers from cement-sand mortar are given in Table 3.

Table 3. Wall characteristics

\begin{tabular}{|c|c|c|c|}
\hline Indicator and unit of measure & \multicolumn{3}{|c|}{ Indicator value } \\
\hline Total wall thickness, $\mathrm{m}$ & 0,45 & 0,5 & 0,55 \\
\hline Thickness of claydite foam concrete, $\mathrm{m}$ & 0,42 & 0,47 & 0,52 \\
\hline $\begin{array}{c}\text { Thickness of cement-sand mortar for } \\
\text { external and internal textured layers, } \mathrm{m}\end{array}$ & 0,03 & 0,03 & 0,03 \\
\hline $\begin{array}{c}\text { Average density of claydite foam } \\
\text { concrete, } \mathrm{kg} / \mathrm{m}^{3}\end{array}$ & 700 & 800 & 900 \\
\hline $\begin{array}{c}\text { Average density of expanded clay } \\
\text { gravel, } \mathrm{kg} / \mathrm{m}^{3}\end{array}$ & 200 & 300 & 400 \\
\hline $\begin{array}{c}\text { Strength of claydite foam concrete, } \mathrm{kg} \\
/ \mathrm{cm} 2\end{array}$ & 50 & 75 & 100 \\
\hline $\begin{array}{c}\text { Thermal resistance of the wall, }\left(\mathrm{m}^{20} \mathrm{C} /\right. \\
\mathrm{W}) .\end{array}$ & 2,45 & 2,40 & 2,35 \\
\hline
\end{tabular}

The constructions of external walls from this lightweight concrete can fully ensure efficient and economical use of energy resources during its operation and provide thermal resistance of external enclosing structures of at least $2.3\left(\mathrm{~m}^{2}{ }^{0} \mathrm{C}\right) / \mathrm{W}$.

\section{Discussions}

The practice of using this concrete has made it possible to identify a number of problems that require additional research:

high variation coefficient of concrete strength and density (up to $20 \ldots 40 \%$ ) associated with high heterogeneity of lightweight filler according to density (this drawback belongs to all types of lightweight concrete and one of the reasons not to use it in structural concretes);

low foamed mass stability in time (the technology is effective when preparing the mixture directly at the place of laying), and hence the heterogeneity of the thermal and strength properties of concrete;

intuitive assessment of porosity degree of the mixture by an operator (the process is not amenable to control directly in the mixer, the degree of porosity depends significantly on 
the flow of water and foaming agent, i.e. on the rheological properties of the concrete mix, and intensive mixing water absorption with light aggregate takes place).

\section{Conclusions}

Lightweight concretes of continuous structure without fine aggregate allow to completely abandon the use of fine aggregate, drastically reduce the density and as a consequence, the thermal conductivity of concrete, reduce the water content and, thus, the release moisture of products, improve cohesion and remolding effect of concrete mix and achieve a number of other advantages.

External walls in residential buildings made of such concrete provide standard thermal resistance and create comfortable conditions for people's lives. At present, lightweight concrete products account for up to $50 \%$ of housing construction volume. The most common are single-layer wall panels, because they are characterized by simple manufacturing technology and low cost. Blocks of expanded clay concrete are also widely used in low-rise housing construction. When building walls from such blocks, half the solution is used, than when building brick buildings. At the same time, the installation speed is increased several times. The walls of light concrete blocks are characterized by their architectural expressiveness and aesthetics, that's why they do not require additional finishing. The durability of lightweight concrete is proved by the example of buildings and structures that have been used for many years.

Numerous advantages of this material give reasons to believe that it will remain in demand in construction for a long time.

\section{References}

1. E.F. Rajaonarison, A. Gacoin, R. Randriana, V.G. Ranaivoniarivo, B.H. Razafindrabe. International Journal of Concrete and Materials, 11, 3 (2017)

2. A. Hanif, Z. Lu, Y. Cheng, S. Diao, Z. Li. International Journal of Concrete and Materials, 11, 1 (2017)

3. G. Cao, Z. Li, K. Guo. Journal of Advanced Concrete Technology, 15 (2017)

4. S. Hatanaka, N. Mishima, A. Maegava, E. Sakamoto. Journal of Advanced, 12 (2014)

5. S. Rath, N. Puthipad, A. Attachaiyawuth, M. Ouchi. Journal of Advanced Concrete Technology, 15 (2017)

6. A.A. Hilal, N.H. Thom, A.R. Dawson. Journal of Advanced Concrete Technology, 14 (2016) 